
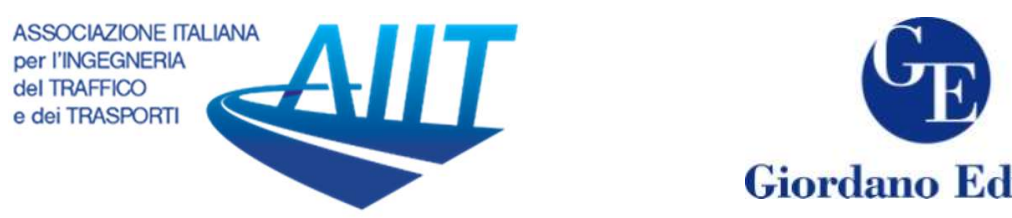

Giordano Editore

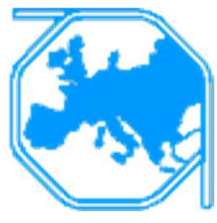

\title{
Tourism and intraregional transport: The assimilation of local transport in tourist destination - the perception of Lisbon's residents
}

\author{
Tiago Rodrigues ${ }^{1 *}$, Alexandra Lavaredas ${ }^{2}$ Nuno Abranja ${ }^{3}$ \\ ${ }^{1} I S C E$ - Instituto Superior de Lisboa e Vale do Tejo \\ ${ }^{2}$ ISCE - Instituto Superior de Lisboa e Vale do Tejo \\ ${ }^{3}$ ISCE - Instituto Superior de Lisboa e Vale do Tejo
}

\begin{abstract}
This article aims to analyze the importance that scientific research has given to tourists' transport, understand the perception of visitors on the adequacy of intraregional transport in the visited destinations, understand the value different type of transports assume in tourist visits, identify the most used means of locomotion in a tourist destination and evaluate the acceptance levels of a tourist transport circuit organized with crossing points at the main touristic attractions, where visitors can leave their vehicles in strategically located car depots. In this case study, 226 valid respondents were considered. The main conclusion of this research is that Portuguese visitors do not consider adequate the supply of public and collective transportation in the national destinations they visit. Not only, most travellers do not use this type of transport to reach a travel destination as, once there, they won't use it. Different factors influence the choice of the travel transportation but if the destination provides efficient supply of collective transportation or environmental vehicles for individual use, visitors are willing to drop their vehicles in car deposits outside touristic centres.
\end{abstract}

Keywords: Tourist destination, Tourist transport circuit, Tourist experience, Sustainability.

\section{Introduction}

Literature review shows evidence that the role transportation plays in the development of touristic destination is being minimized by public authorities (Prideaux, 2000). Being transportation one of the main components of the travelling process, providing efficient transportation solutions is essential to create competitive destinations and sustainable regional development. The present research intends to identify the perception of Portuguese visitors towards the adequacy of the intra-regional transports in the

\footnotetext{
* Corresponding author: Abranja, Nuno (nunoabranja@gmail.com)
} 
destination they visit. To achieve the main objective six intermediate objectives were designed, as follows: i) Analyse the importance scientific research has given to touristic transport; ii) Understand the perception of visitors towards the adequacy of regional and intra-regional transportation in the visited destinations; iii) Understand the value transportation has in touristic visits; iv) Identity the travel mode in a tourist destination; v) Evaluate the importance of the factors that influence the choice of the travel transportation in the touristic destination; vi) Evaluate the level of acceptance of an organised touristic circuit of transportation and/or environmental vehicles for individual use with stopping points in the main touristic attractions, where visitors can leave their vehicles in car deposits.

The literature review will be presented in section two, followed by research methodology and data analysis. Hypothesis testing will be presented in section four and, as a final section, the main conclusions of the study will be discussed.

\section{The Importance of Transport in the Tourist Dynamic of the Tourist Destination}

According to Abranja and Almeida (2009), there is an intimate relationship between tourism and environment, insofar as the former can help to protect the latter. In the absence of planning, the tourist activity can generate some negative impacts, many of which are irreversible. To avoid a situation of prejudice and cultivate a sustainable one, certain environmental protection measures must be applied, such as developing appropriate transport and public service systems. Rosa and Almeida (2019) argue that the mobility of tourists during their stay in a tourist destination presents itself as an increasingly important research topic, due to all the dynamics and actors it involves. In terms of research, this situation seems to be changing, since Prideaux (2000) diagnosed that for many researchers the role of transport in the development of a destination was clearly being neglected.

More recently, ECMT (2000), Jorritsma and Korteweg (2009), Lumsdon (2000), Page (1999) and Thompson and Schofield (2007), cited by Pimenta (2013), considered that the transport of tourists is an area frequently referred to as underestimated, essentially at the urban scale level. Moreover, it is easily noticeable that the transport system continues to be mainly focused on the resident population since according to Pimenta (2013), citing Minghetti and Celotto (2000) and UNWTO (2008), the transport of goods continues to be ignored.

Despite the indicators of change that are envisaged, recent studies continue to demonstrate situations in which public transport continues to be undervalued and used by visitors. According to Rosa and Almeida (2019), little or no use of public transport in their daily lives is essentially associated with difficulty walking (34.3\%). This indicates that a large part of the transport offer continues to be out of alignment with the needs of tourists. It can be assumed that if there is an offer, that offer remains in some cases far from the attractions which forces tourists to walk immensely to reach attractions of tourist interest. According to Rosa and Almeida (2019), the reasons for choosing organized transport on the day of arrival and departure refer essentially to the greater ease and speed of service $(49.9 \%)$ and the fact that they are unaware of public transport at the destination $(38.3 \%)$, which raises the question that often, when there is a public transport offer, it is not used because it is not properly disclosed by agents.

In addition to this lack of disclosure, according to Pimenta (2013), citing ETC (2001), few tourists resort to public transport, preferring other means of transportation such as a 
car, preferable due to the lower associated costs and freedom when traveling. The same author recalls that factors such as flexibility, availability, and the capacity to transport several people and their luggage are evident advantages to this mean of transport. These factors become even more important when traveling with family. Public transport ends up becoming expensive, in addition to not allowing door-to-door transport, which is particularly negative when traveling with luggage. Not forgetting older tourists which are more sensitive to this theme and have been gaining greater expression in the market due to an increasing number of early retirements, as well as greater financial availability. The latter factor increases the desire to travel, making the older age group one of the most significant tourist demand (Pimenta, 2013, citing Korver, 2004). Guiver et al. (2007, cited by Pimenta, 2013) reinforce these ideas, indicating Thompson and Schofield (2002) that cite that are not able to provide a TC service to meet the tourists needs are witnessing an increase in the weight of IT, leading to unsustainable mobility patterns or even lack of desire to return to the destination.

\subsection{Transport and Destination Quality - What Relationship?}

According to the Accessible Destinations Management Manual (Turismo de Portugal, 2017), transport plays a fundamental role for all tourists. Despite this perception, only now it is gaining greater clarity for agents. Prideaux (2000) stated that a destination poorly served by transport would certainly be overlooked by an alternative destination that presents better responses at this level. Nowadays, when the tourist offer in relation to destinations is more and more competitive and we have an increasingly better prepared tourist, and much more demanding, it is very pertinent to understand the weight this factor assumes.

Therefore, it is important to understand the current state of public transport in tourist destinations, and it is even more important to identify the reasons that lead to it not being adjusted to the needs of tourists in many destinations. Moreover, this problem is properly identified since, according to the document by Turismo de Portugal (2018), Strategy 2027 , one of the objectives is to ensure an offer of adequate public transport to the existing tourist intensity. This need is old, but even so, this adaptation is slow to be made since for Cardoso (2011), citing Gunn (1994), the existence of transport and accessibility to one or more destinations are basic elements of a destination.

According to Lohmann and Nguyen (2011), cited by Siqueira (2018), the differences in the geographic morphology of the tourist destination, seasonality, attractions, and other elements will always be factors that will influence the choice of the means of transport adopted and consequently their viability, so the proposal must always be adjusted to each destination. For Cardoso (2011), citing Buhalis (2000), a tourist destination can be defined as an amalgam of tourism products and services consumed under the same brand, offering consumers an integrated experience, which is subjectively interpreted according to several factors, such as the itinerary of the trip, the cultural base, the reason for the visit and previous experiences.

The existence of an organized model does not guarantee a good degree of satisfaction with the tourist destination. Thus, and according to Thompson and Schofield (2007), it is important to provide a means of transport with aspects such as comfort and safety, price and speed. In fact, it is important to analyse whether creating a quality means of transport can bring more visitors to the destination, being almost certain that due to its environmentally friendly use, it will not jeopardize the conservation of physical and 
environmental resources, bringing the possibility that this solution itself it is a new tourist attraction.

Depending on the destination, it is necessary to think about an adjusted solution. Thompson and Schofield (2007) refer that in larger destinations, satisfaction with transport is more related to ease of use than speed or safety. However, there is a common element in tourists' satisfaction with a destination - sustainability. Thompson and Schofield (2007), citing Honey (2002), already identified in studies carried out in the past, the sustainability factor as important in the global satisfaction with the destination, so it is possible to perceive the importance of this aspect in a possible collective tourist transport solution. Here, too, the opportunity arises to underline the relevant role of sustainability since, according to Costa (2011) alone, it constitutes a factor of competitiveness and positioning. Highlighting in this context the model of Ritchie and Crouch (1999), represented in the figure below, which emphasizes this relationship when stating that to be competitive a destination needs to develop policies and strategies that are governed by sustainability.

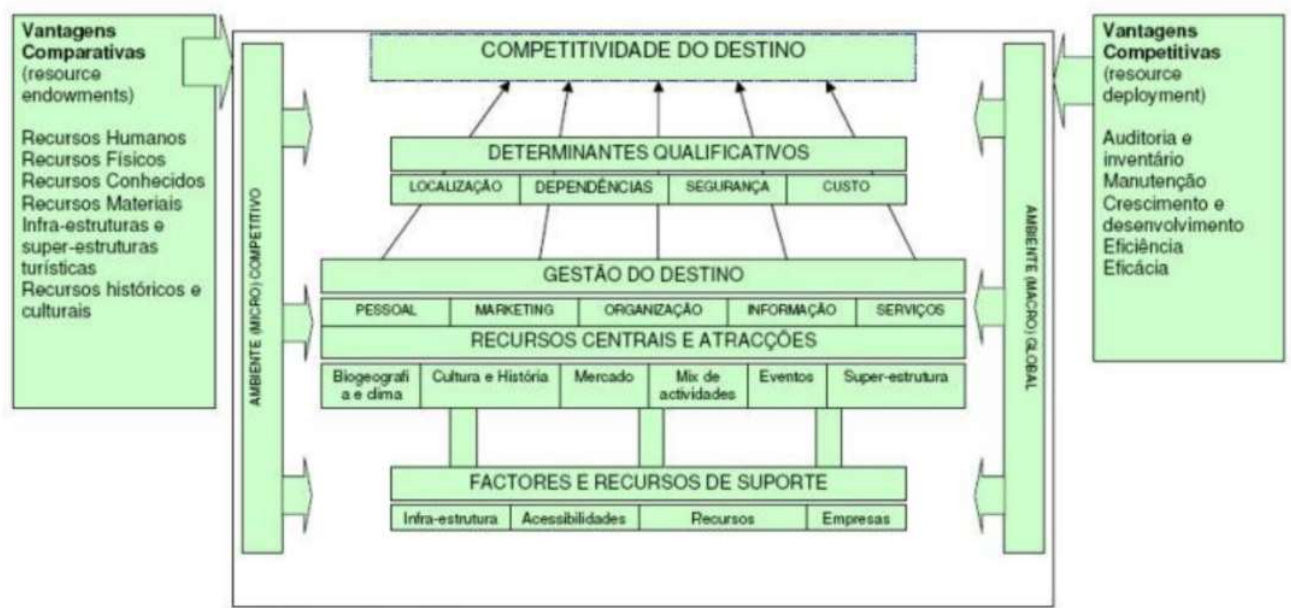

Figure 1: Competitiveness factors of destinations

Source: (Ritchie \& Crouch, 1999, cited by Costa, 2011).

Pimenta (2013), citing OTL $(2009,2010,2011)$ and Reiner et al. (2001), points to the various studies that show the great dissatisfaction of tourists with transport solutions in tourist destinations. Now, if the tourist, in his behaviour, often tries to escape from routine, he will easily choose a destination where stress, noise, air pollution, among others, will not be felt, precisely the problems that tourists face daily (Pimenta, 2013). If we add the poor quality that is often seen in public transport to the other disadvantages easily associated with Public Transport compared to individual transport, there are few arguments to convince tourists to use public transport.

Moreover, according to Cardoso (2011), citing Zabkar et al. (2010), the quality of the attributes of a destination has a positive influence on the total quality of the destination and taking into account that satisfaction has a positive influence on loyalty, then the transport factor has to be taken into account in the destination's offer, being that the worse this aspect is, the greater weight it will have on satisfaction and in turn the further the destiny of "loyalizing" the customer will be. Even because these aspects of accessibility and mobility are directly related to the management of visitors, which, according to Pimenta (2013) citing Manente (2000), allows a more balanced and profitable use of tourist attractions, minimizes the costs associated with their use and it maximizes the 
benefits resulting from the status and value acquired by the famous places, something that we can assume as contributing to the quality of the destination.

According to Rebelo (2016), in theory, if consumers (in this case, tourists) are satisfied with a product, service or brand (tourist destination), there is a greater likelihood that they will repeat the purchase and recommend their experiences to people who surround them, so this satisfaction is fundamental.

\subsection{Transport and Destination Quality - Hand in Hand Accessibility}

For Rosa and Almeida (2019), citing Filimonau, Dickinson and Robbins (2014), as a vital component of the tourism system, a sustainable transport solution is considered essential for sustainable tourism. Pimenta (2013) concludes that the sustainable management of tourism mobility offer can and should be based on the existing soft and collective modes and that information is central to achieving this sustainability, playing a more relevant role than fund solutions and large investments on the path to sustainable tourist travel in cities.

Oliveira (2015) considers that we are therefore heading towards a Sustainable Tourist Destination, in which the tourist potential of each region is considered as the set of tourist services it offers and the natural and cultural characteristics, allowing the construction of spatial networks with activities with concerns destination and where transport plays an important role. According to Costa (2011), citing OMT (2007: 88) if tourism is not developed based on concerns for the sustainability of destinations, undoubtedly it carries the seeds of its own destruction.

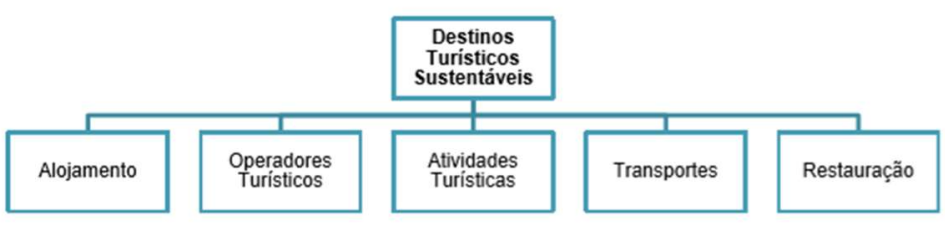

Figure 2: Comprehensive areas of sustainable tourist destinations

Source: Oliveira (2015)

\subsection{Transport as a Mitigating Factor for Mass Tourism in the Tourist Destination}

For Valle et al. (2011) mass tourism has a strong negative impact on the overall satisfaction of tourists and in many cases also impacts on the satisfaction of residents as it deteriorates their quality of life. Overcoming this problem through a means of public transportation accompanied by public policies such as the implementation of pedestrian zones and deposit zones that avoid the concentration of vehicles in areas with a lot of tourist flow can also improve satisfaction with the destination, since hospitality and acceptance by residents has a significant impact on tourist satisfaction. Moreover, the same author considers that the challenges of mass tourism, which are generating reflection in various destinations of choice on the planet, especially in Europe, are varied, albeit with a common denominator: the shock between visitors and quality living conditions of resident populations.

For Davenport and Davenport (2006), cited by Oliveira (2015) together, mass tourism contributes largely to the substantial, and sometimes irreversible, environmental degradation, as well as dramatic social consequences. The majority of ecological 
problems related to tourism and leisure transport is provided by the excessive number of users. According to Costa (2011) sustainability emerges as a development model to be adopted. In addition, in recent years, there has been an intensification of the debate on climate change, thus showing the urgency to adopt this model.

For Pimenta (2013), citing Baysan (2001), the greater environmental awareness of tourists, or the greater culture of recourse to public transport or soft modes in the country of origin, influences the transport options at the destination, leading them to choose more often by public transport, bicycles, and walking, so at a time when environmental issues are very present it will be easier to implement this type of solution. As stated by Oliveira (2015), citing Eurostat (2015), in the case of urban areas the high number of tourists results in congestion, increased levels of pollution and wear and tear on historic buildings. In turn, regarding the consequences in coastal and rural environments, these can be soil erosion, increased waste, discharges into the sea, loss of natural habitats and pressure on protected species.

\section{Research Methodology}

The World Tourism Organization stated at the end of the millennium that tourism research involved the formulation of questions, the gathering of information capable of answering the questions elaborated and the organization and analysis of the data, to understand behaviors, relationships and trends that lead to the perception of the system, decision-making and the construction of various alternative scenarios.

As we saw at the beginning, the general objective of this article was to identify the perception of Portuguese visitors towards the adequacy of intra-regional transport in the destinations they visit. In this framework, specific objectives were defined: i) Analyze the importance scientific research has given to tourism transport (bibliographic review); ii) Understand the perception of visitors on the adequacy of intra-regional transport in the visited destinations (Q6, Q7, Q9, Q10); iii) Understand the value that different types of transport assume in tourist visits (literature review, Q6, Q7, Q9, Q10); (iv) Identify the most commonly used locomotion means in a tourist destination (Q5.1, Q8); v) Assess the factors (and their degree of importance) that influence the choice of transport used by visitors in the visited destinations (Q12, Q13); vi) Evaluate the levels of acceptance of an organized tourist transport circuit and/or the use of environmental vehicles for individual use with points of passage at the main tourist attractions, where visitors can leave their vehicles in car depots (bibliographic review, Q10, Q11).

The present research is based on a descriptive-exploratory methodology and focus on a case study, applied to the residents of the district of Lisbon. The sample represents around $0,010 \%$ of the population. Nevertheless, and because data analysis methodology focus on descriptive statistics, conclusions can only be valid for this specific sample. More than aiming to extrapolate results to the entire universe, the authors' objective is to understand the phenomenon in study. It is intend to launch the basis for a future quantitative research where a representative sample can be used and significance statistics tests can be applied. Ethical premises that guide scientific research have been guaranteed to all participants during data collection. Confidentiality and anonymity in responses and access to data after publication have also been assured.

In this case study, qualitative and quantitative data have been used. Bibliographic analysis allowed the authors to assess the importance that scientific research has given to tourism transport. A online structured questionnaire, was the methodology used to collect 
primary data representative of a specific group of subjects. This instrument was structured with 13 closed questions of quantitative genesis in line with the research questions of the study, especially in determining a categorization and relationship between dependent and independent variables, in order to lead us to understand the perception of visitors on the adequacy of intra-regional transport in the destinations they visit and to know the levels of acceptance of an organized tourist transport circuit.

Data collection was carried out during the month of May 2020, with an online distribution, collecting 226 valid respondents. This instrument was distributed in bulk through the authors' social networks, allowing the voluntary participation of a random sample. The choice of this distance route for obtaining data was supported by the numerous advantages that we were able to derive from this channel, such as: control under the sample, preparation of the questionnaire, diversity of questions, flexibility and convenience of the process, cost reduction, ease of control and monitoring, sample size and scope, data analysis and overall management of the participation of individuals in the study (Evans \& Mathur, 2005). This instrument was composed of 13 closed-range multiple choice questions (Q1, Q2, Q3, Q4, Q4.1, Q4.2) and multiple open-range choice (Q5, Q5.1, Q8), in which we guided respondents in a specific direction for the hypotheses under study, also an open answer question (Q0) referring to the municipality of residence, and also questions of evaluation or estimation, on a Likert scale (Q6, Q7, Q9, Q10, Q11, Q12, Q13), to obtain psychometric answers with assessment of the degree of agreement of respondents in relation to the variables indictive and demonstrating personal position (Joshi \& Pal, 2015).

A pre-test was applied in this survey to 10 subjects, randomly chosen to collect valid opinions that would help us verify the structure, texts and clarity of interpretation of the instrument and to correct any situations that contribute to its improvement. We have collected several suggestions related to the introductory text, answer options and common expressions that made the questionnaire more appropriate for the study. All respondents answered that the instructions were clear, the language was legible and, in general, they considered reading and filling out the survey easy and expressed their liking of its format.

The application of this instrument proved to be fundamental in the collection of the primary data essential for research, since the opinions of its participants were extremely quantitative and argumentative in the overall results of the study.

A non-random sampling method was considered the most convenience sampling method for this study, as proposed by Etikan, Musa \& Alkassim (2016). Although this technique presents some limitations strongly related to the fact that the results are limited to the individuals surveyed, it was the method chosen because it was available to researchers due to the confinement of populations forced by the pandemic situation that occurred in the second quarter of 2020.

The sample of our study is thus composed of 226 individuals, equally distributed in terms of gender (female $(57.1 \%)$; male $(42.9 \%)$ ), with predominance in the age groups $35-44(32.6 \%), 45-54(21.4 \%)$ and 25-34 (17\%), with different academic qualifications, although the majority with a degree (43.8\%).

A coherent research course was defined which led researchers to make progress in exploratory readings, helping them to overcome prejudices and create work hypothesis. We present these hypothetical statements with the correspondence of the research objectives: H1 - Visitors consider appropriate the intra-regional transport of the visited destinations; H2 - Good accessibility and mobility conditions add value to tourist destinations; H3 - Different factors influence the choice of transports means used by 
visitors in the visited destinations; $\mathbf{H 4}$ - If the destination makes environmental vehicles for individual use available to the tourist demand, visitors admit to leave their cars in car depots outside the touristic centres; H5 - With an efficient offer of public transport at the destination, visitors admit to leave their cars in car depots outside the tourist centres; H6 - The pandemic caused by the Covid 19 virus negatively influences the willingness of visitors to use public transport during their tourist trips.

\section{Analysis and Income Statement}

Through descriptive statistics as the base procedure in this study, the main results of the descriptive analysis of data are presented, through absolute and relative frequency distribution tables collected through the 226 surveys by questionnaire.

When we asked our participants about the Portuguese region they visit most often, we found that Algarve collects 34.1\% of the choices of our respondents, Alentejo 21.7\%, Oporto and North of Portugal 16.4\%, Centro Region 15.5\%, Lisbon Region 10.6\%, Madeira $1.3 \%$ and Azores $0.4 \%$. Then we questioned the frequency that our participants practise tourism in their country each year, in non-pandemic context. The responses were expressive and quite enlightening: $110(48,7 \%)$ participants answered 1 to 2 times and $31.4 \%$ said they practised tourism in Portugal 3 to 4 times per year. $18.6 \%$ of the individuals reported performing 5 or more times tourist visits in the national territory and only 3 respondents said they did not do 'inside' tourism. Similarly, we wanted to know how long, on average, it takes our respondents to visit a city or village, when they practise tourism within the country. Most subjects (43.4\%) answered 2 or 3 days, $33.2 \%$ responded 1 to 2 days, $10.6 \%$ chose 4 to 5 days and a very small slice makes its holiday in Portugal longer.

Question 5 was intended to identify the form of locomotion that our participants use most frequently to travel to the destination they visit in Portugal. Results showed that 'Own car' was the choice indicated by 194 respondents (85.8\%). The other answer options divided the remaining preferences. In the same context, question 5.1 aimed to know the form of locomotion that our sample uses most predominantly to move within the visited Portuguese regions. In this case, there was a more equitable distribution, although with a greater tendency in choosing the option 'Own car '(43.8\%), 'On foot '(34.5\%). Only 3.1\% selected 'Public transport'. It should be noted that $13.3 \%$ of respondents answered "Anyone. It depends on the distance to be visited', revealing openness in the option to choose according to the concrete context.

It was important for this study to understand how our participants are attached to different elements of the destination, when selecting a region of Portugal to visit. It was quite evident that the 'Attractions (places to visit)' brought together the preference of the study sample, with 131 respondents (58\%) selecting "Very important" and $88(38.9 \%)$ individuals choosing the "Important" answer option. Then comes the element 'Accommodation' to have greater weight in the choice of destination, with 118 respondents $(52.2 \%)$ answering "Very important" and $100(44.2 \%)$ choosing the "Important" answer option. With regard to the core of this study - Transport -, it is clear that there is no coherence in the responses among our sample, because only $19.3 \%$ of the individuals answered "Very important" and 28.8\% opted for "Important". Still in relation to transport, the most chosen answer option was "Not very important", by $32.6 \%$ of the subjects, which, when added to those who answered "Nothing important", practically half of the answers $(47 \%)$. 


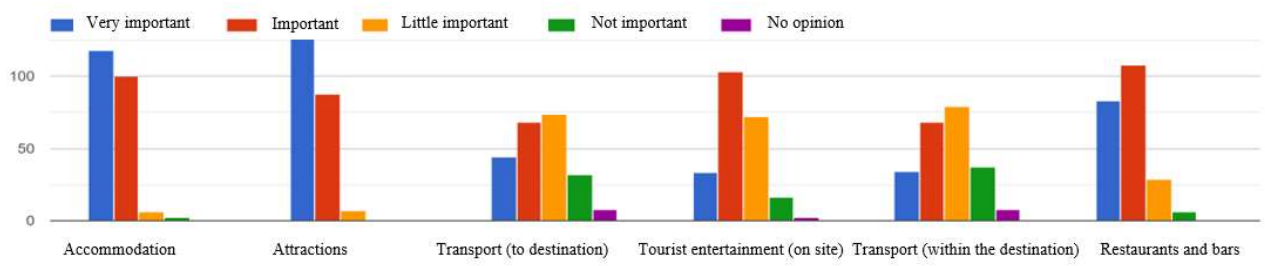

Figure 3: Q6. When you select a destination in Portugal to visit, what importance do you attach to each of the following elements?

Self- elaboration

When we asked our participants the importance they attached to another set of elements when selecting a destination in Portugal to visit the result was ineffable. We found that 'Price' is the most unanimous factor among our sample when it comes to choosing the national destination to visit, with 130 (58\%) people considering it "Very important" and another 87 (38.5\%) individuals to choose "Important". Only 3.5\% of respondents said it was "Not important". However, other factors that stand out, due to the high number of responses in the "Important" option, are 'Accessibility (to destination)' (59.3\%), 'Sustainability on site' (59.7\%) and 'Accessibility/Mobility (within the destination)' (49.6\%). If we add to these the answers given in the option "Very important", we will have, in total, the element 'Accessibility (to the destination)' with $84 \%$, the factor 'Sustainability in place' with $82.7 \%$ and the component 'Accessibility/Mobility (within the destination)' with $73.5 \%$. Also add that in the element 'Fashion/Status' $40 \%$ of the subjects indicated "Little important" and 39.4\% "Not important, revealing with these results to support their decision in their own opinion and not in the pressure of society.

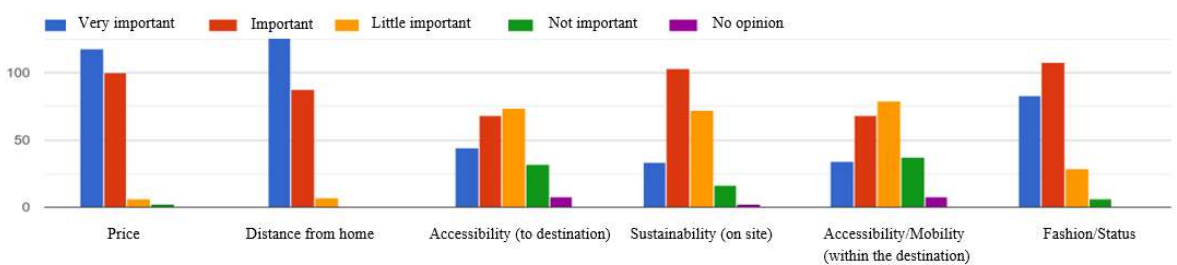

Figure 4: Q7. When you select a destination in Portugal to visit, what importance do you attach to each of the following elements?

Self-elaboration

In question 8, we asked about the preferred alternative way of locomotion of our respondents within the national destination visited if they could not use their own vehicle. The vast majority chose to travel on foot $(53.5 \%)$ but, $23.5 \%$ replied that it depended on the distance to be travelled to, leaving open the availability that visitors have in taking advantage of other means of transportation. We emphasize that 'Public transport (metro, bus, taxi, etc.)' collected only $14.6 \%$ of preferences and 'Public transport (hop on hop off, bus tours, shuttle, etc.)' even less $(4,6 \%)$. It thus appears that both public transport and tourism are not the preferred means of intra-regional travel of our sample. 

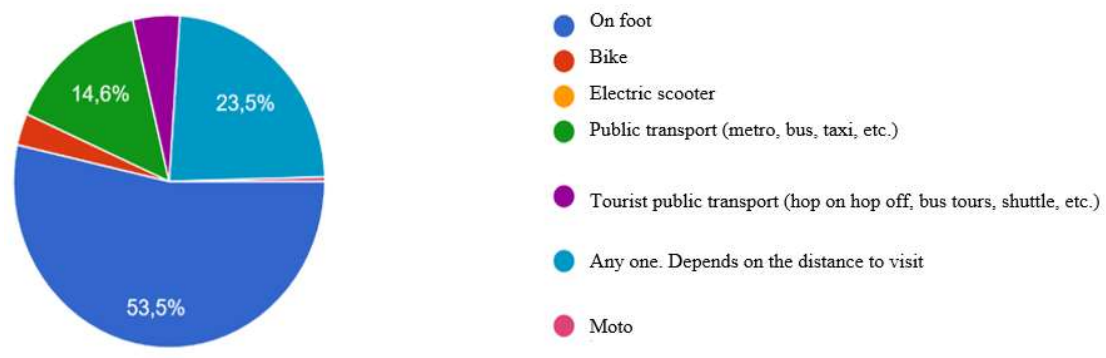

Figure 5: Q8. If you cannot use your own car INSIDE a destination when you are touring in Portugal, what is your preferred alternative locomotion method?

Self-elaboration

We also wanted to assess the evaluation that our respondents make of the elements we presented regarding the Portuguese destinations they visit more. Many of the opinions are not positive and $23 \%$ of the participants chose not to express an opinion. Regarding 'Public transport (metro, bus, taxi, etc.)" $43.8 \%$ of participants selected "Good", but only $5.7 \%$ chose the "Excellent" option, revealing a median satisfaction among our participants. It is important to highlight that $21.2 \%$ answered that public transport was "Weak" and 6.2\% "Bad". 52 (23\%) individuals did not express an opinion. As for "Tourist public transport (hop on hop off, bus tours, shuttle, etc.)' the results are very similar and the conclusions we can draw are practically the same. Regarding the aspects 'Control of access of individual road vehicles to the city/town centre', 'Environmental concerns of the destination in terms of road traffic', 'Parking accessible outside the city/town' and 'Good mobility alternatives within the city' city/town to be able to leave the car outside', we found that the majority of our sample chose the option "Good", with 41.6\%, 43.4\%, $45.6 \%$ and $35.5 \%$ respectively. Many participants (between 29\% and 33\%) have chosen the option "Weak" for the same aspects listed. Regarding the remaining three elements of question 9, it should be noted that the answer option "Weak" was the most selected among our respondents, although in a low way compared to the next option ("Good") of the rating scale/estimation. This reveals some dissatisfaction about the 'Public transport timetables within the visited region', the 'Public transport circuit within the visited region (passage in the main tourist attractions)' and the 'Adequacy of the public transport offer and looking for visitors within the region visited'.

It was also the purpose of this article to evaluate the opinion of our respondents regarding transport, as tourists in Portugal. We were able to observe that preferences are very consonant among the sample when questioned about the consumption of public or individual public transport, as well as tourist transport, and we found that the vast majority $(62 \%)$ do not consume these means of travel. We noticed that $34.5 \%$ of the respondents reported not using these means of transport due to the high price, but the majority $(52 \%)$ disagreed that the price was the reason for not using it. Notwithstanding these results, when we asked the study participants to indicate their opinion on the estimation scale to the statement 'I am a great advocate of public transport (metro, bus, taxi, etc.) and I think that all visitors should use them in tourism regions.' and 'I am a strong advocate of tourist transport (hop on hop off, bus tours, shuttle, etc.) and I think that all visitors should use them in tourism regions.'. We found that despite many do not consume, as we saw above, $64.2 \%$ and $56.2 \%$ of the subjects, respectively, agree with both statements. It is worth highlighting the results that stand out about the "Individual transport contributes to the 
increase in pollution in any region'. We've found that the overwhelming majority $(87.2 \%)$ agrees with the statement, having 53\% selected the option "I totally agree". Results also show the agreement of our participants ( $84 \%$ of responses) when asked if they thought that smaller tourist cities/towns should close road traffic in historic/residential centres and provide alternative parking abroad, as well as public transportation to visit the main points of interest. The participants mostly express environmental concerns and openness to accept suitable sustainable solutions.

Question 11 - 'If you cannot use your own vehicle within a destination in Portugal, to what extent would you accept the following proposals?' - This question was very important for this study, since it elucidated us about the respondents' ability to accept the alternatives that we've presented, regarding the means of transportation within the visited region. We note, therefore, that 50.4\% answered "Yes, no doubt" and 44.7 "Yes, perhaps", to the challenge of leaving their vehicle in a warehouse/parking located outside the city/town to visit it. Only 5\% answered that they did not. About visiting the destination on a collective tourist transport circuit provided by the municipality, $50 \%$ of the sample indicated "Yes, no doubt", 45.6 "Yes, perhaps" and only 4.4 declare that they did not. The biggest highlight is the result of the answers given to the third statement of this question - 'Visiting the destination in environmental vehicles for individual use (scooters, bicycles, electric cars, etc.) made available by the municipality', where we observed that $58.8 \%$ of subjects answered "Yes, no doubt", 34.1 "Yes, perhaps" and only 4.8 chose the option "No". From this, we can conclude that there is a wide opening of our sample to travel alternatives within the region to visit in our country, even more if it is in environmentally friendly vehicles.

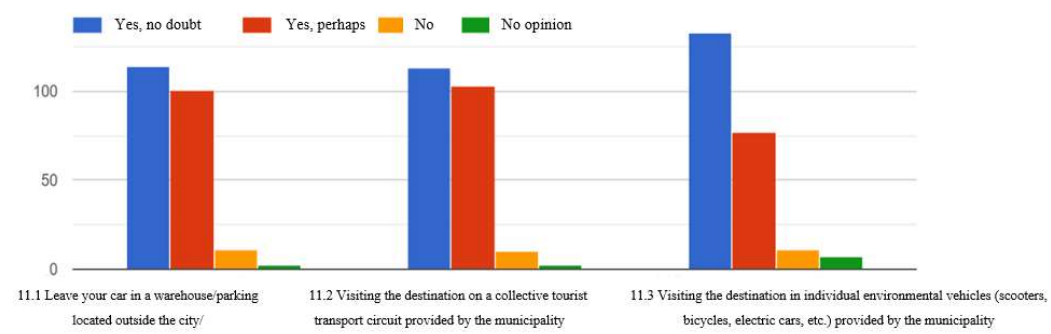

Figure 6: Q11. If you cannot use your own car WITHIN a destination in Portugal, to what extent would you accept the following proposals?

Self-elaboration

We also wanted to know the amount that our respondents would be willing to pay, per day, to leave their vehicles in a deposit/parking located outside the city/town and visit the destination in a collective tourist transport circuit or in an individual environmental vehicle (scooters, bicycles, electric cars, etc.) provided by the municipality. We have noted that the majority of participants would pay between $0 €$ and $5 €(42.5 \%), 33.3 \%$ chose to indicate " $5 €-10 €$ " and $8.8 \%$ chose " $10 €-20 €$ ". It should be noted that $10.1 \%$ of the individuals selected $0 €$ as the answer option and no one indicated the option $30 €$ or more. 


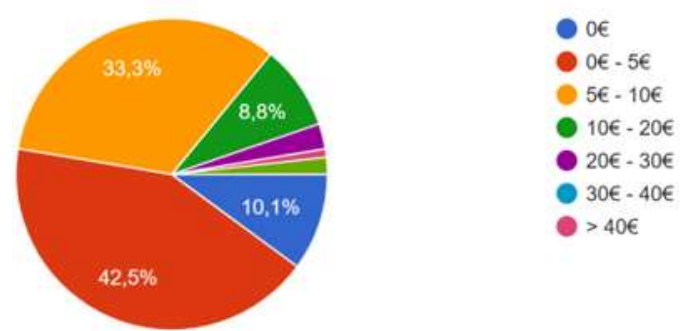

Figure 7: Q11.1 Following the previous question, what amount would you be willing to pay, per day, to leave your car in a warehouse/parking lot located outside the city/village and visit the destination on a collective tourist transport circuit or in individual environmental vehicle (scooters, bicycles, electric cars, etc.) provided by the municipality?

Self-elaboration

It was also the objective of this study to specify the importance that our participants give to a certain set of factors of a circuit of collective tourist transport or in environmental vehicles for individual use (scooters, bicycles, electric cars, etc.), when visiting a Portuguese destination. Considering the total numbers of choices for the option "Very important" in each evaluated element, 'Safety' (74.3\%) and 'Hygiene' (73.9\%) are the most important components for our sample, followed by 'Waiting time' (68.1\%), 'Price' (63.3\%), 'Frequent transport' and 'Stops close to tourist attractions', both with 59.7\%, and 'Environmental sustainability' (55.8\%). Although we note here the results of the totals of the "Very important" answer option in the listed elements, it is necessary to emphasize that the number of selections of the "Important" option follows the trend of the respondents' preferences, which, together, would always give above $85 \%$. Equally pertinent but with higher numbers of "Important" compared to the total of "Very important", are the factors 'Travel convenience', 'Speed of travel' and 'Quality of vehicles'. It should be emphasized that the answer options "Little important", "Not important" or "No opinion" have no expression in the result.

Finally, we considered relevant to try to identify whether the current pandemic situation would influence the opinion of our respondents regarding the assessment and use of public and tourist collective transport in tourism. Responses show that $71.7 \%$ of the subjects ("I totally agree": $38,5 \%$; "Agree": $33.2 \%$ ) state that their opinion regarding the use of transport changed with the appearance of Covid-19 and 23\% disagree ("Totally disagree": 6.6\%; "Disagree": 16.4\%). Only 6.2\% have no opinion. Regarding the statements that allowed us to perceive the degree of comparison between the consumption of public and collective tourist transport in previous, current and future tourist visits, the responses are substantially divided by the various levels of estimation and a high abstention has been registered. 


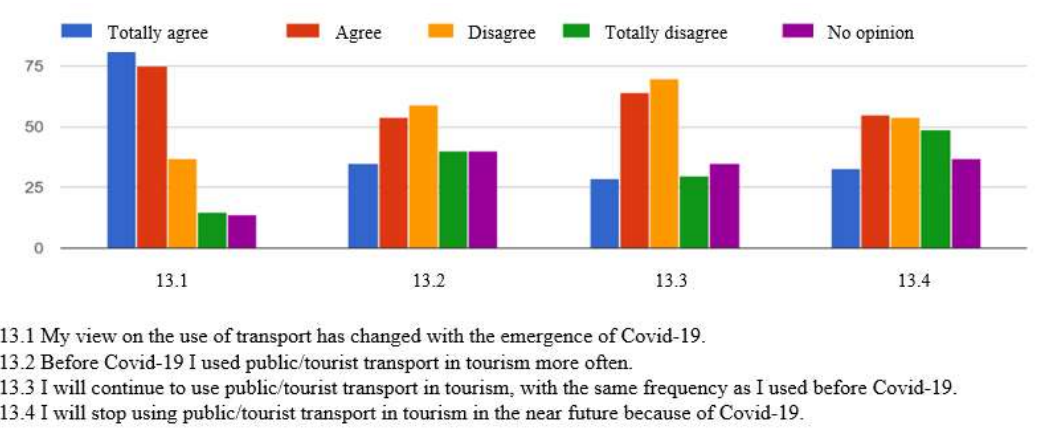

Figure 8: 13. Given the current pandemic situation, indicate the option that best reflects your choice.

Self-elaboration

The scenario that this figure gives us may reveal that it is still premature to predict people's decisions in terms of the use of public transport and collective tourism in the regions they visit, considering the context of instability that we are experiencing today and all the uncertainty that exists about tourist mobility.

\subsection{Hypothesis Testing and Discussion}

The purpose of the study was to identify the Portuguese visitor's perception of the adequacy of intra-regional transports in the destinations they visit. Six hypotheses were proposed and subsequently tested among Lisbon residents. Regarding the data provided in the previous section, four of them were supported, one rejected, and one hypothesis was inconclusive.

The first hypothesis tested the adequacy of intra-regional transports in the destinations where respondents travel the most and will help researchers to understand objective two: understand the perception of visitors towards the adequacy of regional and intra-regional transportation in the visited destinations. The satisfaction most of our travellers have towards the supply of public and collective transportation, in touristic destinations, is satisfactory or unsuitable for the touristic needs.

As for the following factors, this study shows that travellers are mediumly satisfied: (i) The control of access to private vehicles to the city/village centre; (ii) Environmental policies for road traffic in the destination; (iii) Accessible parking lots outside the city/village; (iv) Suitable mobility alternatives inside the city/village so that car can be parked outside the centre. About the schedules or the itinerary of public transportation evaluation, visited regions do not meet the tourists' needs, who rate these items as weak.

Since not all conditions were met, hypothesis one was rejected- 'Visitors do not consider adequate the supply of intra-regional transportation in the destinations they visit the most'. Although hypothesis one was rejected it was still important to understand the value transportation has in touristic visits (objective three).

Although scholars suggest that collective transportation helps touristic destinations to better position themselves among its competitors (Costa, 2011) and it is vital for the sustainability of the tourism industry (Rosa \& Almeida, 2019; Filimonau, Dickinson \& Robbins, 2014), the results of our study are inconclusive. Around $47 \%$ of respondents consider that transportation is not an important factor of the travel destination. On the other hand, $48 \%$ of participants consider it as an important or very important factor. Despite this incongruence it is important to note that accessibility, sustainability, and 
mobility were considered important influence factors in the travel decision making process, for more than $70 \%$ of travellers. Therefore, we cannot support or reject hypothesis two - 'Good accessibility and mobility add value to touristic destinations'. Further research needs to be conducted.

Objectives four and five aim to identity the travel mode in a touristic destination and evaluate the importance of the factors that influence the choice of the travel transportation in the touristic destination. Results show that very few travellers use public transport to reach their travel destination, preferring a private vehicle to reach the place they want to visit. When confronted with the interdiction of driving in the touristic destination, tourists prefer to travel on foot, depending on the distance. Using public or collective touristic transportation would be the choice of a maximum of $14 \%$ of the travellers.

Factors like safety, hygiene, waiting time, price, frequency, stop near touristic attractions, environment sustainability, comfort, speed, quality of vehicles are important or very important factors for travellers if choosing public transportation to travel in the touristic destinations. This study reinforces the argument of Thompson e Schofield (2007) who claim that public transportation must provide a good balance of comfort, safety, price, and speed. We are now in position to support hypothesis three 'Different factors influence the choice of the travel transportation used by visitors in the touristic destinations.

Objective six intends to evaluate the level of acceptance of an organised touristic circuit of transportation and/or environmental vehicles for individual use, with stopping points in the main touristic attractions, where visitors can leave their vehicles in car deposits. Results show that $62 \%$ of respondents believe that small cities/villages should close their road traffic in historical/residential centres. Around $95 \%$ of participants said to be willing to accept the alternative of leaving the car in a parking lot outside the city/village centre and paying for that up to 10 euros. Results also showed that travellers are ready to use public collective transportation provided by public institutions. These findings support both hypothesis four 'If the destination provides environmental vehicles for individual use, visitors admit dropping their vehicles in car deposits outside touristic centres' and hypothesis five 'With efficient supply of collective transportation in destinations, visitors admit leaving their vehicles in car deposits, outside touristic centres'.

Due to the pandemic situation the world is living researchers believed this could influence results. So, one last hypothesis has been included in the analysis and the data provided in the previous section supported hypothesis six 'The pandemic caused by virus Covid-19, has a negative influence in the mood of visitors to use public collective transportation during their touristic displacements.

\section{Concluding Remarks}

The main conclusion of this study is that Portuguese visitors do not consider adequate the supply of public and collective transportation in the destinations they visit in their country. Not only, most travellers do not use this type of transport to reach a travel destination as, once there, they still will not use it.

Different factors influence the choice of the travel transportation but if the destination provides efficient supply of collective transportation or environmental vehicles for individual use, visitors are willing to drop their vehicles in car deposits outside touristic 
centres. Mobility, accessibility, and sustainability are in the mind of travellers and should also be included in regional development policies.

Travel solutions of collective and individual public transportation in touristic destination should go further to meet demand and environmental needs. However, the inconclusive findings of the value added by good accessibility and mobility in touristic destinations, plus the pandemic scenario that the world is living lead researchers to believe that predictions about decisions travellers will make concerning the transport to use to reach and to move in the travel destination should be done with precaution.

It would be desirable, in a future study, to compare the results with other Portuguese regions and nearby countries, such as Spain and France, where there are also many tourist regions with mobility and transport problems.

\section{References}

Abranja N., Almeida I. (2009) “Turismo e Sustentabilidade”, Cogitur, Journal of Tourism Studies, 2 (2), pp. 15-31.

Almeida C. \& Rosa M. (2019). Perfil e Mobilidade dos Turistas Seniores durante a sua Estadia no Algarve. Tourism and Hospitality International Journal, 13(1), pp. 106130.

Cardoso, J. (2011). Avaliação da Qualidade de Destinos Turísticos: Destino Figueira da Foz, $M s C$ thesis, Universidade de Aveiro, Aveiro.

Costa, I. (2011) O Marketing Turístico Sustentável na Perspectiva das Comunidades Locais: o Pólo de Desenvolvimento Turístico da Serra da Estrela. MsC thesis, ISCTE, Lisboa.

Etikan I., Musa S. A., Alkassim, R. S. (2016) "Comparison of Convenience Sampling and Purposive Sampling”, American Journal of Theoretical and Applied Statistics. 5 (1), pp. 1-4.

Evans, J. R., Mathur, A. (2005). The Value of Online Surveys. Zarb School of Business, Hofstra University, Hempstead, New York, USA.

Joshi, A., Pal D- K. (2015) "Likert Scale: Explored and Explained. British Journal of Aplplied Science \& Tecnology. 7 (4), pp. 396-403.

Oliveira, V. (2015) Modo de Gestão para a Sustentabilidade de Destinos Turísticos Análise do Caso de Estudo de Percursos da Região de Sintra-Cascais, MsC thesis, Instituto Superior Técnico, Lisboa.

Pimenta, R. (2013). Acessibilidade e Turismo Urbano no Caso de Lisboa, MsC thesis, Universidade Nova, Lisboa.

Prideaux, B. (2000) "The Role of the Transport System in Destination Development", Tourism Management, 21, pp. 53-63.

Rebelo, A. (2016) Análise do Comportamento do Consumidor no Turismo: Uma Abordagem Geracional da Procura Turística nos Açores, $M s C$ thesis, Universidade dos Açores. Ponta Delgada.

Siqueira, G. (2018) Proposta de Treinamento aos Colaboradores das Empresas Aéreas, com base na Análise da Gestão da Hospitalidade no Transporte Aéreo: Um Estudo de Caso das Empresas Aéreas no Aeroporto Afonso Pena, MsC thesis, Universidade Federal do Paraná. Panamá. 
European Transport $\backslash$ Trasporti Europei (2021) Issue 83, Paper n 2, ISSN 1825-3997

Thompson, K., Schofield, P. (2007) "An Investigation of the Relationship Between Public Transport Performance and Destination Satisfaction", Journal of Transport Geography, 15 (2), pp. 136-144.

Turismo de Portugal (2017) "Estratégia 2027. Liderar o Turismo do Futuro", Working Paper, Turismo de Portugal, I. P. 